\title{
Neuroprotective Effects of Inositol 1,4,5-Trisphosphate Receptor C-Terminal Fragment in a Huntington's Disease Mouse Model
}

\author{
Tie-Shan Tang, ${ }^{1}$ Caixia Guo, ${ }^{2}$ Hongyu Wang, ${ }^{1} \mathrm{Xi}$ Chen, ${ }^{1}$ and Ilya Bezprozvanny ${ }^{1}$ \\ Departments of ${ }^{\text {Physiology and }}{ }^{2}$ Pathology, University of Texas Southwestern Medical Center at Dallas, Dallas, Texas 75390
}

\begin{abstract}
Huntington's disease (HD) is a dominantly inherited, progressive neurodegenerative disease caused by an expanded polyglutamine tract in huntingtin protein (Htt). Medium spiny striatal neurons (MSNs) are primarily affected in HD. Mutant huntingtin protein $\left(\mathrm{Htt}{ }^{\mathrm{exp}}\right)$ specifically binds to and activates type 1 inositol 1,4,5-trisphosphate receptor $\left(\mathrm{InsP}_{3} \mathrm{R} 1\right)$, an intracellular $\mathrm{Ca}^{2+}$ release channel. $\mathrm{Htt}^{\mathrm{exp}_{-}}$ Ins $\mathrm{P}_{3} \mathrm{R} 1$ association is mediated by a cytosolic $\mathrm{C}$-terminal tail of $\mathrm{InsP}_{3} \mathrm{R} 1$ (a 122-aa-long IC10 fragment). To evaluate an importance of $\mathrm{Htt}^{\mathrm{exp}}$ association with Ins $\mathrm{P}_{3} \mathrm{R} 1$ for $\mathrm{HD}$ pathology, we generated lentiviral and adeno-associated viruses expressing GFP-IC10 fusion protein and performed a series of experiments with YAC128 HD transgenic mouse. Infection with Lenti-GFP-IC10 virus stabilized $\mathrm{Ca}^{2+}$ signaling in cultured YAC128 MSNs and protected YAC128 MSNs from glutamate-induced apoptosis. Intrastriatal injections of AAV1GFP-IC10 significantly alleviated motor deficits and reduced MSN loss and shrinkage in YAC128 mice. Our results demonstrate an importance of $\operatorname{Ins}_{3} \mathrm{R} 1-\mathrm{Htt}^{\mathrm{exp}}$ association for $\mathrm{HD}$ pathogenesis and suggested that Ins $\mathrm{P}_{3} \mathrm{R} 1$ is a potential therapeutic target for HD. Our data also support potential use of IC10 peptide as a novel HD therapeutic agent.
\end{abstract}

Key words: calcium signaling; neurodegeneration; $\mathrm{InsP}_{3} \mathrm{R}$; recombinant adeno-associated virus (AAV); Huntington's disease; transgenic mouse; stereology

\section{Introduction}

Huntington's disease (HD) is an autosomal-dominant neurodegenerative disorder characterized by chorea, psychiatric disturbances, and gradual but inexorable intellectual decline to death 15-20 years after onset (Vonsattel and DiFiglia, 1998; Young, 2003). The cause of $\mathrm{HD}$ is an expanded polyglutamine (polyQ) expansion in the $\mathrm{N}$ terminus of huntingtin protein $(\mathrm{Htt})$ (The Huntington's Disease Collaborative Research Group, 1993). The polyQ expansion leads to a toxic gain of function in $\mathrm{Htt}^{\mathrm{exp}}$ protein, which results in selective death of striatal medium spiny neurons (MSNs) (Vonsattel and DiFiglia, 1998; Tobin and Signer, 2000). A number of toxic functions have been assigned to $\mathrm{Htt}^{\mathrm{exp}}$, such as effects on gene transcription, formation of toxic aggregates, direct induction of apoptosis, disruption of key neuronal functions such as proteasomal or mitochondrial functions, ubiquitination pathways, axonal transport, endocy-

Received Sept. 15, 2008; revised 0ct. 23, 2008; accepted Dec. 20, 2008.

I.B. is a holder of the Carla Cocke Francis Professorship in Alzheimer's Research and supported by National Institutes of Health (NIH) Grants NS38082 and NS056224, the CHDI Foundation, the Robert A. Welch Foundation, and the McKnight Neuroscience of Brain Disorders Award. The University of lowa Gene Transfer Vector Core was supported by the NIH and the Roy J. Carver Foundation. The monoclonal anti-InsP $\mathrm{P}_{3} \mathrm{R} 1$ antibody $\mathrm{L} 24 / 18$ was developed and obtained from the University of California, Davis/National Institute of Neurological Disorders and Stroke/ $\mathrm{Na}$ tional Institute of Mental Health NeuroMab Facility supported by NIH Grant U24NS05060. We thank Xiangmei Kong, Huarui Liu, and Yuemei Li for help with maintaining the YAC128 mouse colony, Li Li and Jing Liu for help with vira injections and mouse behavior experiments, Janet Young and Leah Benson for administrative assistance, Maria Scheel and the University of lowa Gene Transfer Vector Core for AAV vectors and advice on AAV production, and David Self for help and advice on stereotaxic injections.

Correspondence should be addressed to Dr. llya Bezprozvanny at the above address. E-mail: ilya.bezprozvanny@utsouthwestern.edu.

D01:10.1523/JNEUROSCI.4411-08.2009

Copyright $\odot 2009$ Society for Neuroscience $\quad 0270-6474 / 09 / 291257-10 \$ 15.00 / 0$ tosis, and synaptic transmission (Tobin and Signer, 2000; Ross, 2002; Harjes and Wanker, 2003; Sugars and Rubinsztein, 2003). However, the main cause of MSN degeneration in HD still remains unclear. In our previous studies we demonstrated that mutant $\mathrm{Htt}^{\mathrm{exp}}$ specifically binds to and facilitates activity of type 1 inositol 1,4,5-trisphosphate receptor $\left(\mathrm{InsP}_{3} \mathrm{R} 1\right)$ (Tang et al., 2003), indicating that abnormal neuronal $\mathrm{Ca}^{2+}$ signaling may play an important role in HD pathogenesis (Bezprozvanny and Hayden, 2004). These ideas were further supported by our studies of neuronal $\mathrm{Ca}^{2+}$ signaling and apoptosis in primary MSN cultures from the YAC128 transgenic HD mouse model (Tang et al., 2005, 2007; Wu et al., 2006; Zhang et al., 2008). Mutant $\mathrm{Htt}^{\mathrm{exp}}$ specifically binds to the C-terminal cytosolic region of InsP $\mathrm{P}_{3} \mathrm{R} 1$ (the IC10 fragment) (Tang et al., 2003). Thus, we reasoned that introduction of IC10 peptide into HD MSNs in trans should disrupt pathogenic association between Ins $\mathrm{P}_{3} \mathrm{R} 1$ and $\mathrm{Htt}^{\mathrm{exp}}$, normalize neuronal $\mathrm{Ca}^{2+}$ signals, and prevent cell death of HD MSNs. To test this hypothesis we used viral vectors to introduce GFP-IC10 fusion protein into YAC128 MSNs both in vitro and in vivo. We found that expression of GFP-IC10 protein stabilized neuronal $\mathrm{Ca}^{2+}$ signaling and protected YAC128 MSNs from glutamate-induced apoptosis, alleviated motor deficits, and reduced neuronal pathology in YAC128 HD mice. These results support an importance of $\mathrm{Ins}_{3} \mathrm{R} 1-\mathrm{Htt}{ }^{\text {exp }}$ association for $\mathrm{HD}$ pathogenesis and validate $\mathrm{InsP}_{3} \mathrm{R} 1$ as a novel therapeutic target for $\mathrm{HD}$ treatment.

\section{Materials and Methods}

YAC128 mice and primary MSN cultures. All animal studies were approved by the University of Texas Southwestern Medical Center Animal 


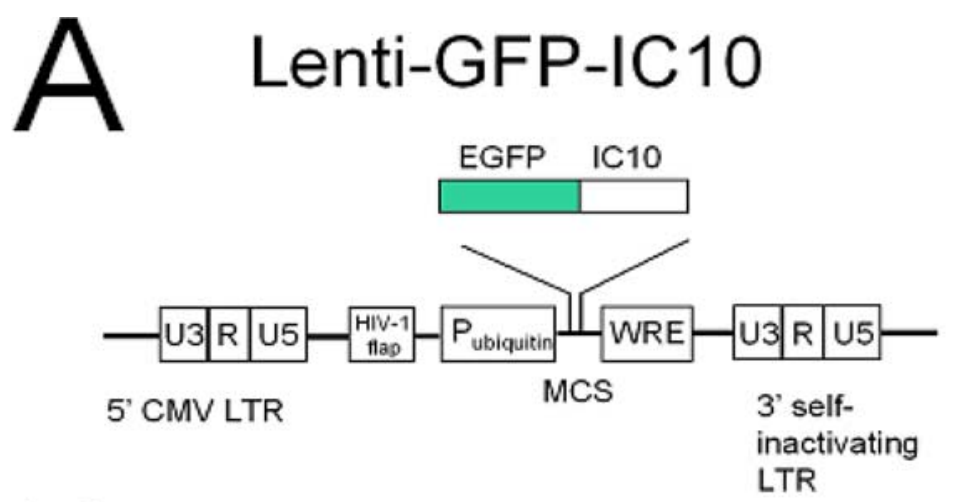

$\mathrm{B}$

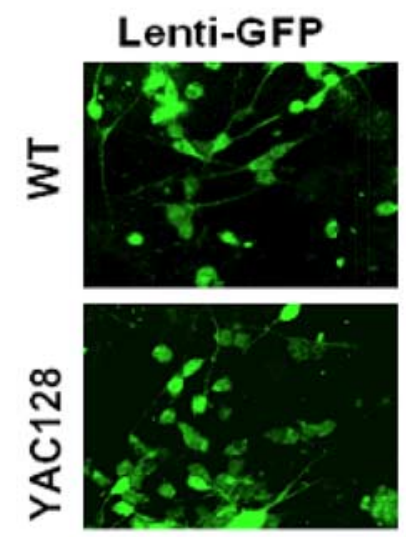

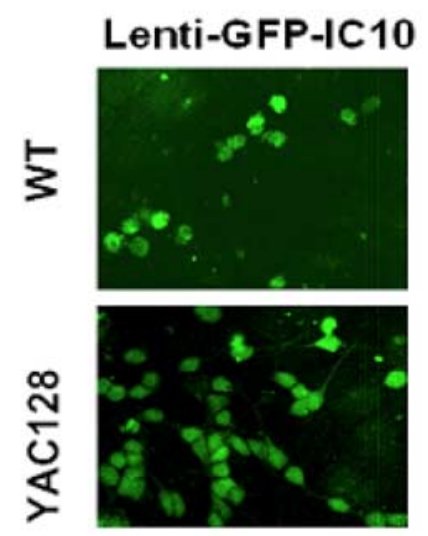
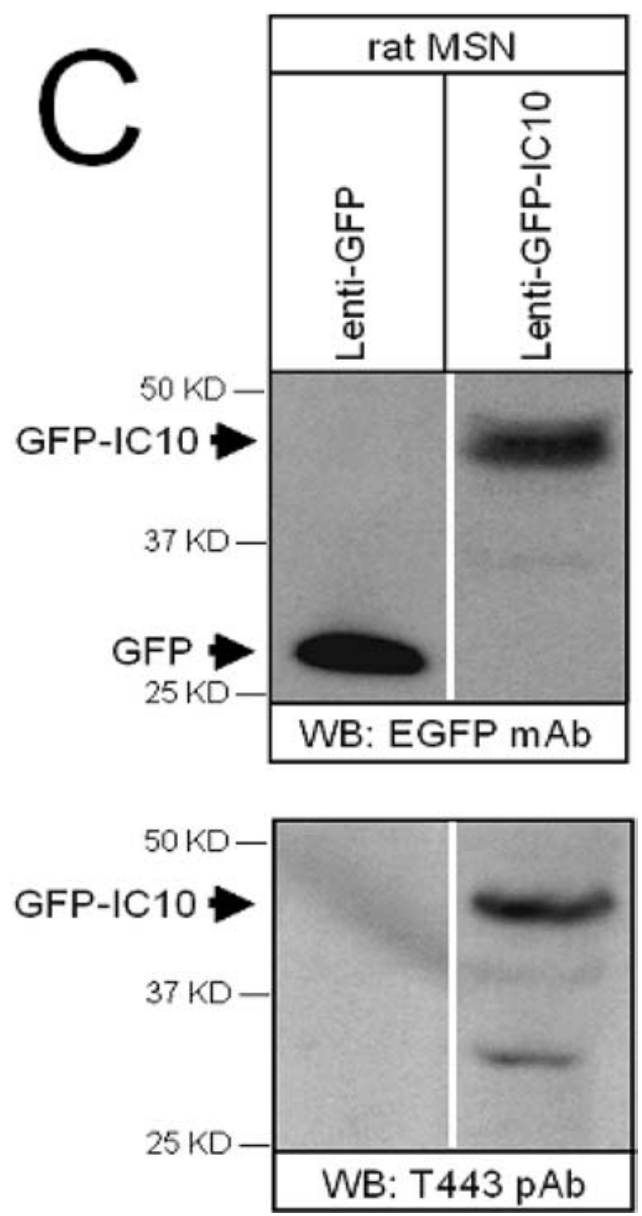

Figure 1. Generation and validation of Lenti-GFP and Lenti-GFP-IC10 viruses. A, Cloning strategy for Lenti-GFP-IC10 and Lenti-GFP shuttle plasmid. B, GFP imaging of WT and YAC128 MSNs infected with Lenti-GFP and Lenti-GFP-IC10 viruses. C, Western blotting of MSN cultures infected with Lenti-GFP and Lenti-GFP-IC10 viruses. The cells were lysed $48 \mathrm{~h}$ after infection and analyzed by Western blotting with anti-GFP mAb and T443 pAb against InSP ${ }_{3}$ R1. MSN cultures in 24-well plates were infected with $\sim 2 \times 10^{7}$ ip/well of Lenti-GFP virus or Lenti-GFP-IC10 virus.

Care and Use Committee. Generation and breeding of YAC128 transgenic mice (FVBN/NJ background strain) were previously described (Slow et al., 2003). Heterozygous male YAC128 mice were crossed with the wild-type (WT) female mice and resulting litters were collected at postnatal day 1 . The pups were genotyped by PCR with primers specific for exons 44 and 45 of human Htt gene, and the MSN cultures of WT and YAC128 mice were established and maintained as we previously described (Tang et al., 2005, 2007; Wu et al., 2006; Zhang et al., 2008).

Generation of lentiviral vectors. IC10 fragment of rat $\mathrm{InsP}_{3} \mathrm{R} 1(\mathrm{~F} 2627-$ A2749, 122 aa in length) (Tang et al., 2003) was amplified by PCR and cloned into pEGFP-C3 expression vector (Clontech). EGFP protein and EGFP-IC10 fragment were excised from pEGFP-C3 and subcloned into ubiquitin promoter-driven lentiviral shuttle vector. Generated constructs were sequenced. Lenti-GFP and Lenti-GFP-IC10 viruses were made by cotransfection of shuttle vectors with HIV-1 packaging vector 8.9 and VSVG envelope glycoprotein plasmids into the packaging cell line HEK293T. The titer of generated lentiviruses was $\sim 10^{8}$ infection particles (ip)/ml for Lenti-GFP and $\sim 2 \times 10^{7} \mathrm{ip} / \mathrm{ml}$ for Lenti-GFP-IC10.

$\mathrm{Ca}^{2+}$ imaging experiments. Fura- $2 \mathrm{Ca}^{2+}$ imaging experiments with $13 \mathrm{~d}$ in vitro (13DIV) MSN cultures were performed as we previously described (Tang et al., 2005) using a DeltaRAM illuminator, an IC-300 camera, and ImageMaster Pro software (all from PTI). Briefly, the cultured MSNs were maintained in artificial CSF (aCSF) $(140 \mathrm{~mm} \mathrm{NaCl}, 5$ $\mathrm{mM} \mathrm{KCl}, 1 \mathrm{~mm} \mathrm{MgCl}_{2}, 2 \mathrm{mM} \mathrm{CaCl}_{2}$, and $10 \mathrm{~mm} \mathrm{HEPES}$, pH 7.3) at $37^{\circ} \mathrm{C}$ during measurements (PH1 heater, Warner Instruments). Fura-2 340/ 380 ratio images were collected every $6 \mathrm{~s}$ for the duration of the experiment. Baseline (1-3 min) measurements were obtained before first pulse of glutamate. The $10 \mu \mathrm{m}$ glutamate solution was dissolved in aCSF and 1 min pulses of $37^{\circ} \mathrm{C}$ glutamate solution $(\mathrm{SH}-27 \mathrm{~B}$ in-line solution heater,
Warner Instruments) were applied by using a valve controller (VC-6, Warner Instruments) driven by a square-pulse electrical waveform generator (Model 148A, Wavetek).

TUNEL-TMR experiments. TUNEL experiments with 14DIV MSN cultures were performed as previously described (Tang et al., 2005) with slight modifications. MSN cultures from WT and YAC128 mice were infected with Lenti-GFP $\left(1.8 \times 10^{6} \mathrm{ip} /\right.$ well $)$ or Lenti-GFP-IC10 $(2.1 \times$ $10^{6} \mathrm{ip} /$ well) at 7DIV and 11DIV. Control cells were incubated with vehicle solution. At 14DIV, MSNs were exposed to 0, 100, or $250 \mu \mathrm{M}$ glutamate for $7-8 \mathrm{~h}$, fixed, permeabilized, and analyzed by TUNEL-TMR staining (DeadEnd Fluorometric TUNEL System, Promega) and DAPI nuclear counterstaining. The fractions of TUNEL-positive nuclei were determined by manual counting as previously described (Tang et al., 2005), and the results are presented as means \pm SE. For Lenti-GFP- or Lenti-GFP-IC10-infected MSNs, fraction of TUNEL-TMR-positive nuclei was scored only for GFP-positive cells.

Generation of AAV1 vectors. The AAV1-GFP and AAV1-GFP-IC10 viruses were generated in Sf9 cells (Urabe et al., 2002) by following University of Iowa Gene Transfer Vector Core protocols. CMV-GFP-BGH or CMV-GFP-IC10-BGH expression cassettes were subcloned to adenoassociated shuttle vector pFBGR (Xia et al., 2004; Harper et al., 2005). Recombinant baculoviruses bac-GFP and bac-GFP-IC10 were generated using Bac-to-Bac system (Invitrogen). Bac-GFP and bac-GFP-IC10 viruses were used to infect $\mathrm{Sf} 9$ cells together with Rep2 and Cap1 viruses. The AAV1-GFP and AAV1-GFP-IC10 viruses were collected from lysed Sf9 cells and purified by Iodixanol gradient centrifugation (Zolotukhin et al., 1999) followed by Mustang-Q membrane ion exchange (Pall Corporation). The purified AAV1 viruses were concentrated on Amicon Ultra-4 membrane. The titers of generated viruses were $6.8 \times 10^{11}$ 

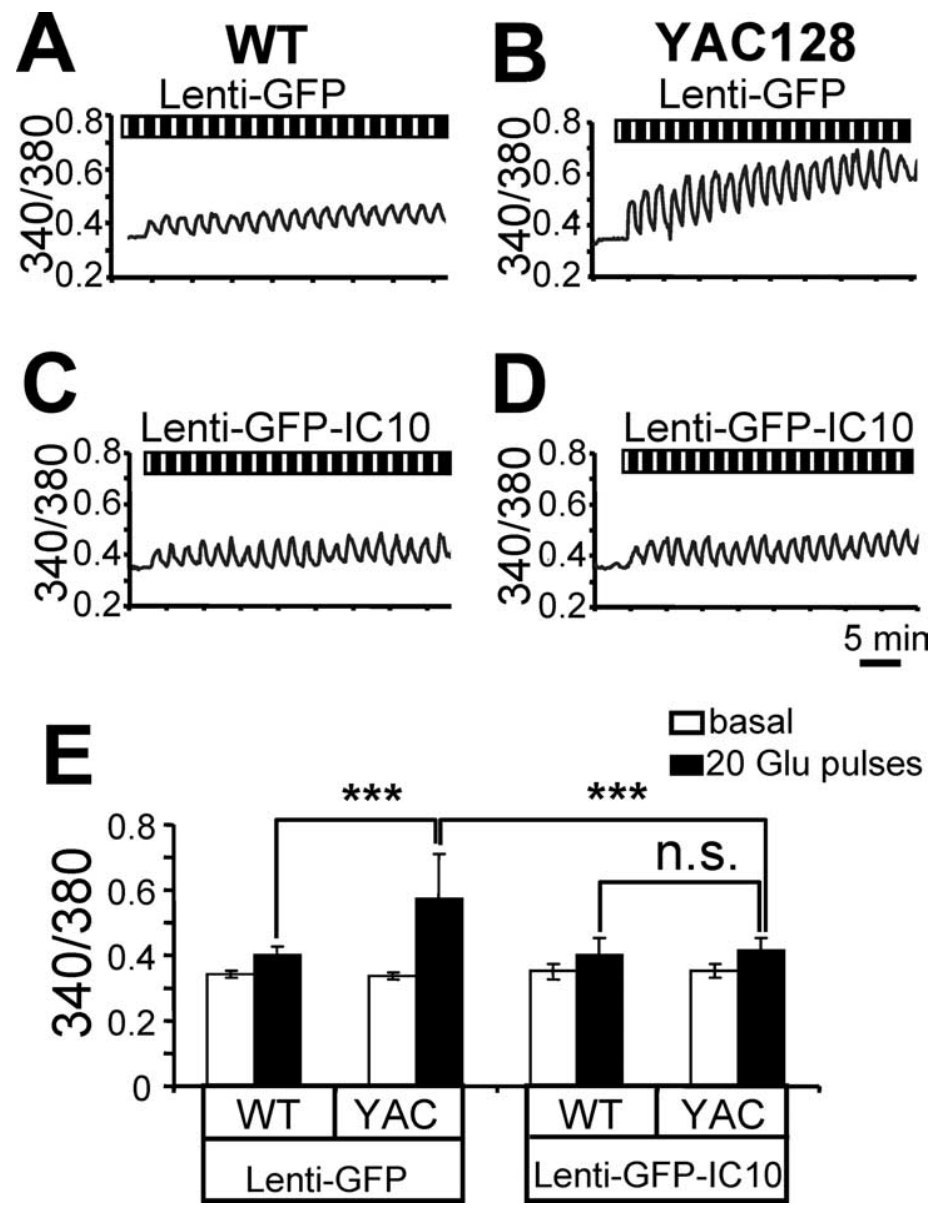

Figure 2. Expression of GFP-IC10 stabilizes $\mathrm{Ca}^{2+}$ signaling in YAC128 MSNs. $A, B$, Repetitive application of $10 \mu \mathrm{m}$ glutamate induces $\mathrm{Ca}^{2+}$ signals in Lenti-GFP-infected MSNs from the WT $(\boldsymbol{A})$ and YAC128 $(\boldsymbol{B})$ mice. $\boldsymbol{C}, \boldsymbol{D}$, The same experiment as in $\boldsymbol{A}$ and $\boldsymbol{B}$ was performed with WT $(\boldsymbol{C})$ and YAC128 (D) MSNs infected with Lenti-GFP-IC10 viruses. Cytosolic $\mathrm{Ca}^{2+}$ levels in $\boldsymbol{A}-\boldsymbol{D}$ are presented as a 340/380 fura-2 ratio. Each pulse of glutamate is shown as a black bar (1 $\mathrm{min})$, and the washout step is shown as a white bar $\left(1 \mathrm{~min}\right.$ ) above the $\mathrm{Ca}^{2+}$ trace. The traces shown are averaged 340/380 traces from all MSNs for each experimental group. $\boldsymbol{E}$, The average basal $\mathrm{Ca}^{2+}$ levels (mean $\pm \mathrm{SD} ; n$ is the number of MSNs analyzed) before (open bars) and after (filled bars) 20 pulses of $10 \mu \mathrm{m}$ glutamate are shown for WT/GFPMSNs $(n=46)$, YAC128/GFP MSNs $(n=50)$, WT/GFP-IC10 MSNs $(n=45)$, and YAC128/GFP-IC10 MSNs $(n=42)$ as indicated. After 20 pulses of $10 \mu$ m glutamate, the $\mathrm{Ca}^{2+}$ levels in YAC128/GFP MSNs are significantly $(* * * 00.05)$ higher than in WT/GFP and YAC128/GFP-IC10 MSNs. Lenti-GFP-IC10 infection had no significant effect on $\mathrm{Ca}^{2+}$ signals in WT MSNs. n.s., Not significant.

$\mathrm{TU} / \mathrm{ml}$ for AAV1-GFP and $6.0 \times 10^{11} \mathrm{TU} / \mathrm{ml}$ for AAV1-GFP-IC10 as determined by the HT1080 cell infection assay.

Stereotaxic injections of $A A V 1$ viruses. The striatal stereotaxic injections of AAV1 viruses were performed as described (Harper et al., 2005) For bilateral injections the injection syringes were positioned at a $10^{\circ}$ angle on both sides of the brain. We empirically determined that the optimal injection coordinates (relative to bregma) for striatal injections were anterior/posterior $=0.5 \mathrm{~mm}$, lateral $=2.5 \mathrm{~mm}$, dorsal $/$ ventral $=-2.8$ $\mathrm{mm}$. The AAV1 viruses were dialyzed against lactated Ringer's solution $\left(130 \mathrm{~mm} \mathrm{Na}^{+}, 109 \mathrm{~mm} \mathrm{Cl}^{-}, 28 \mathrm{~mm}\right.$ lactate, $4 \mathrm{~mm} \mathrm{~K}^{+}$, and $3 \mathrm{mM} \mathrm{Ca}^{2+}$ ) immediately before stereotaxic injections. The final viral titers used for injection were $2.2 \times 10^{11} \mathrm{TU} / \mathrm{ml}$ for AAV1-GFP and $2.0 \times 10^{11} \mathrm{TU} / \mathrm{ml}$ for AAV1-GFP-IC10 in the lactated Ringer's solution. The injection volumes were $4 \mu \mathrm{l}$ per site, $0.2 \mu \mathrm{l} / \mathrm{min}$ infusion rate. AAV1 injections were performed in 7-to 8-week-old mice. A total of 60 mice were injected with AAV1-GFP (15 mice for WT, 15 mice for YAC128 mice) and AAV1GFP-IC10 (15 mice for WT, 15 mice for YAC128 mice). Two weeks after injection and surgery, 57 mice were alive and fully recovered.

Coimmunoprecipitation and Western blot analysis. Striata from YAC128 mice were dissected 2 months after AAV1-GFP and AAV1-GFPIC10 injection, homogenized, and solubilized at $4^{\circ} \mathrm{C}$ for $2 \mathrm{~h}$ in $0.5 \mathrm{ml}$ of extraction buffer A [1\% CHAPS, $137 \mathrm{~mm} \mathrm{NaCl}, 2.7 \mathrm{~mm} \mathrm{KCl}, 4.3 \mathrm{~mm}$
$\mathrm{Na}_{2} \mathrm{HPO}_{4}, 1.4 \mathrm{~mm} \mathrm{KH} \mathrm{PO}_{4}(\mathrm{pH}$ 7.2), $5 \mathrm{~mm}$ EDTA, 5 mM EGTA, and protease inhibitors]. The homogenates were cleared by $30 \mathrm{~min}$ centrifugation at 50,000 rpm in TL-100 and incubated with anti-Ins $\mathrm{P}_{3} \mathrm{R} 1$ polyclonal antibodies (T443) attached to protein-A Sepharose CL-4B beads (GE Healthcare) at $4^{\circ} \mathrm{C}$ for $3 \mathrm{~h}$. The resulted beads were washed three times with extraction buffer $A$ and analyzed by Western blotting with anti-human/mouse $\mathrm{Htt} \mathrm{mAb}$ (1:2000; MAB2166, Millipore Bioscience Research Reagents). The same membrane was stripped and reblotted with anti-human/monkey $\mathrm{Htt} \mathrm{mAb}$ (1:2000; MAB2168, Millipore Bioscience Research Reagents) and anti-Ins $\mathrm{P}_{3} \mathrm{R} 1 \mathrm{mAb}$ (NeuroMab 75-035). For evaluation of recombinant protein expression, injected mice were killed every 2 months after injection, and the striatal lysates were prepared as described above. Thirty-five micrograms of protein were run on SDS-PAGE gel as described, and then probed with $\mathrm{mAb}$ against EGFP (1:2000; Covance). The same nitrocellulose membrane was stripped and reprobed with $\mathrm{pAb}$ antibodies against $\mathrm{Ins}_{3} \mathrm{R} 1 \mathrm{C}$ terminus to detect IC10 fragment [T443 pAb, 1:1000, raised against peptide R2731-A2749, corresponding to the 18 most C-terminal amino acids in the rat $\mathrm{InsP}_{3} \mathrm{R} 1$ sequence (Kaznacheyeva et al., 1998)].

Motor coordination assessments. Mice injected bilaterally with AAV1-GFP or AAV1GFP-IC10 at 7-8 weeks of age were analyzed by balance beam at 3, 5, 7, 9, and 11.5 months of age. The "beam-walking" assay was performed as we previously described (Tang et al., 2007) The $11 \mathrm{~mm}$ round beam and $5 \mathrm{~mm}$ square beam were used in our studies. The mice were trained to traverse the beam to the enclosed box. Once the stable baseline of performance was obtained, the mice were tested in two consecutive trials on the $11 \mathrm{~mm}$ round beam and $5 \mathrm{~mm}$ square beam. The latency to traverse the middle section $(80 \mathrm{~cm}$ in length) of each beam and the number of times the hind feet slipped off each beam were recorded for each trial. For each measure, the mean scores of the two trials for each beam were used in the analysis.

The footprint test was performed at 11.5 months time point as we previously described (Tang et al., 2007). In these experiments the hindfeet and forefeet of the mice were coated with blue and purple nontoxic paints, respectively. The mice were then trained to walk along a $50-\mathrm{cm}$-long, $10-\mathrm{cm}$-wide open-top runway (with $10-\mathrm{cm}$ high walls) into an enclosed box. All mice were given 3 runs/d for 3 consecutive days. A fresh sheet of white paper was placed on the floor of the runway for each run. The footprint patterns were assessed quantitatively by four measurements: stride length, hind base width, front base width, and front/hind footprint overlap as described previously (Tang et al., 2007).

Neuropathological assessments. The neuropathological assessments in striatal region were performed as we described previously (Tang et al., 2007). At conclusion of behavioral testing (11.5-12 months time point), the mice were terminally anesthetized and perfused transcardially with $10 \mathrm{ml}$ of $0.9 \%$ saline followed by $100 \mathrm{ml}$ of fixative (4\% paraformaldehyde in $0.1 \mathrm{~m}$ PBS, pH 7.4). All brains were removed from skull and weighed. The brains were postfixed overnight at $4^{\circ} \mathrm{C}$ in $4 \%$ paraformaldehyde and equilibrated in $20-30 \%(\mathrm{w} / \mathrm{v})$ sucrose in PBS. The brains were sliced to $30-\mu \mathrm{m}$-thick coronal sections using a Leica SM2000R sliding microtome. The sections were mounted in Dako Glycergel Mounting Medium (Dako). The coronal sections spaced $360 \mu \mathrm{m}$ apart throughout 

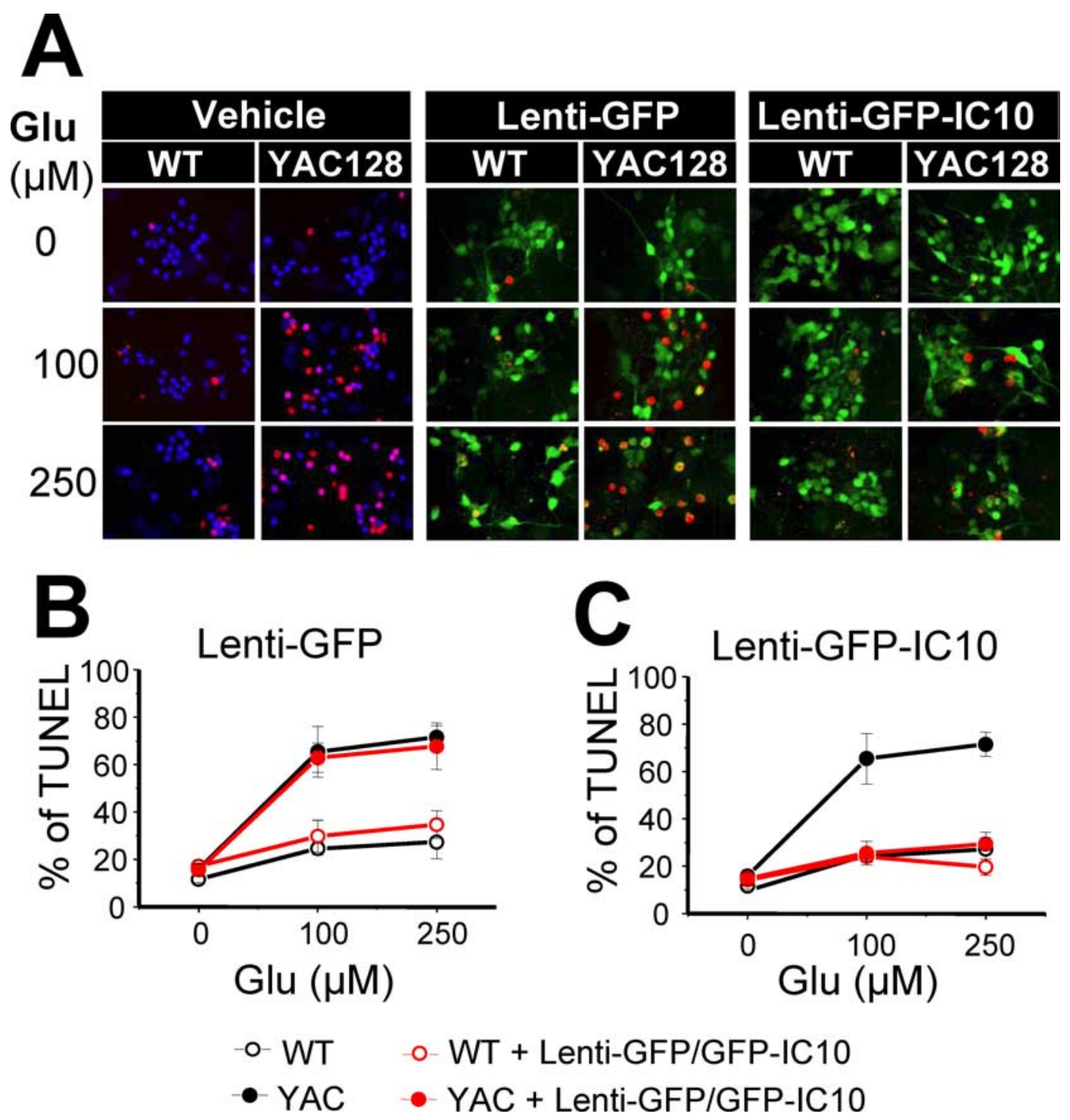

Figure 3. Expression of GFP-IC10 protects YAC128 MSNs from glutamate-induced apoptosis. A, MSNs from the WT and YAC128 mice were exposed to the vehicle solution or infected with Lenti-GFP or Lenti-GFP-IC10 viruses at 7DIV and 11DIV. At 14DIV, MSNs were exposed to 0, 100, or $250 \mu \mathrm{m}$ glutamate for $7-8 \mathrm{~h}$, fixed, permeabilized, and analyzed by TUNEL-TMR staining (red) and DAPI nuclear counterstaining (blue). B, C, The fraction of TUNEL-positive nuclei (shown in $\boldsymbol{A}$, red) was determined and plotted against glutamate concentration for WT (open circles) and YAC128 (filled circles) MSNs with vehicle solution (black) or lentivirus addition (red). At each glutamate concentration, the data are shown as mean \pm SE $(n=4-6$ microscopic fields, $200-300 \mathrm{MSNs}$ per field). At 100 and $250 \mu \mathrm{m}$ glutamate, the fractions of TUNEL-positive MSNs are significantly $(p<0.05)$ higher for YAC128/vehicle and YAC128/GFP than for WT/GFP or YAC128/GFP-IC10. Similar results were obtained with three separate WT and YAC128 MSN cultures and infections.

the striatum (in the range from $+1.70 \mathrm{~mm}$ to $-2.30 \mathrm{~mm}$ relative to bregma) were stained with NeuN monoclonal antibody (1:1000 dilution; Millipore) and biotinylated anti-mouse secondary antibodies (1:200 dilution; Vector Laboratories) (MOM kit). Signal was amplified with an ABC Elite kit (Vector Laboratories) and detected with diaminobenzidine (Pierce Biotechnology). All quantitative stereological analyses were performed blindly with respect to the nature of slices (genotype and drug feeding) using Stereoinvestigator setup and software (MicroBrightField). The grid size was set to $450 \times 450 \mu \mathrm{m}$, and the counting frame was set to $50 \times 50 \mu \mathrm{m}$. The $60 \times$ microscope objective was used for counting. The average slice thickness after histological processing was determined to be $22 \mu \mathrm{m}$. The guard depth was set to $6 \mu \mathrm{m}$ on top and $4 \mu \mathrm{m}$ on bottom. The neuronal cross-sectional area was estimated by nucleator probe under the optical fractionator. Nucleator rays were set to 6 . The entire striatum regions were analyzed by unbiased stereology.

Light microscopy assessment of aggregates. The coronal brain sections of $30 \mu \mathrm{m}$ thickness were mounted in Dako Glycergel Mounting Medium (Dako) and stained with anti-Htt MAB5374 monoclonal antibody (1: 1000 dilution; Millipore Bioscience Research Reagents) and biotinylated anti-mouse secondary antibodies (1:200 dilution; Vector Laboratories) (MOM kit). The signal was amplified with an ABC Elite kit (Vector Laboratories) and detected with diaminobenzidine for the presence of aggregates (Vector Laboratories). The nuclear huntingtin staining in brain sections was analyzed by brightfield microscopy.

Statistical data analysis. For comparison between two groups, Student's unpaired $t$ test was used to statistically analyze data. For comparison between more than two groups, ANOVA followed by post hoc Fisher's PLSD test was used.

\section{Results}

Expression of GFP-IC10 stabilizes $\mathrm{Ca}^{2+}$ signaling in

YAC128 MSNs

The IC10 C-terminal fragment of InsP $\mathrm{P}_{3} \mathrm{R} 1$ (F2627-A2749, 122 aa in length) directly and specifically binds to mutant $\mathrm{Htt}^{\exp }$ (Tang et al., 2003). We reasoned that introduction of IC10 peptide into HD MSNs in trans should disrupt pathogenic association between InsP $\mathrm{P}_{3} \mathrm{R} 1$ and $\mathrm{Htt}^{\text {exp }}$ and enable us to test an importance of 

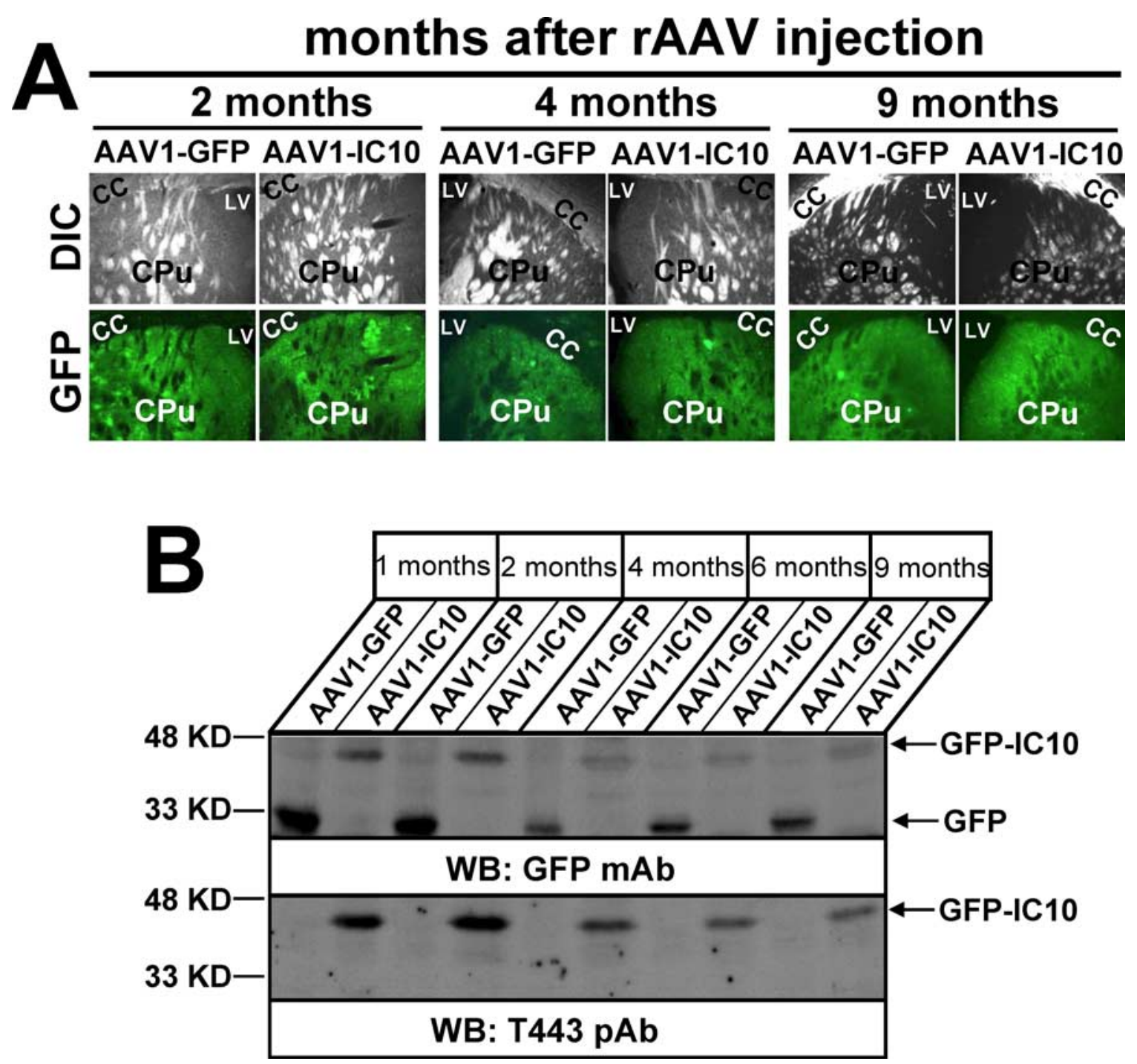

Figure 4. Sustained striatal expression in AAV1-injected mice. A, GFP imaging analysis of AAV1-GFP or AAV1-IC10. The WT mice were injected at 2 months of age and transcardially perfused at 2,4, and 9 months following AAV1 injection. The brains were collected, fixed, sliced to $30 \mu \mathrm{m}$ coronal sections, and analyzed by GFP imaging. CC, Corpus callosum; LV, lateral ventricle; CPu, striatum. $B$, Western blotting analysis of striatal GFP and GFP-IC10 expression. The WT mice were injected at 2 months of age and analyzed by Western blotting of striatal lysates at 1, 2, 4, 6, and 9 months following AAV1 injection. GFP and GFP-IC10 expression were analyzed by Western blotting of striatal lysates with anti-GFP mAb (top) and T443 anti-InsP ${ }_{3} R 1$ pAb (bottom). Thirty-five micrograms of total protein was loaded on each lane.

$\mathrm{InsP}_{3} \mathrm{R} 1-\mathrm{Htt}^{\mathrm{exp}}$ association for $\mathrm{HD}$ pathogenesis. To introduce IC10 peptide into terminally differentiated striatal neurons, we generated lentiviral vectors encoding GFP-IC10 fusion protein (Fig. 1A). In biochemical experiments we determined that IC10 fragment is stabilized in soluble form by addition of N-terminal GFP or GST tag (data not show). Thus, the N-terminal GFP tag in our experiments is used to maintain IC10 in a soluble form and also to help in identification of infected neurons. As a control, we also generated lentiviruses encoding GFP protein alone (Fig. $1 \mathrm{~A}$ ). The titer of generated lentiviruses was equal to $10^{8} \mathrm{ip} / \mathrm{ml}$ for Lenti-GFP and $2 \times 10^{7} \mathrm{ip} / \mathrm{ml}$ for Lenti-GFP-IC10. Efficient infection of wild-type and YAC128 MSNs by Lenti-GFP and LentiGFP-IC10 viruses was confirmed in GFP imaging experiments (Fig. $1 B$ ). The correct expression of GFP-IC10 and GFP proteins in cultured MSNs was further confirmed by Western blotting with anti-GFP mAb and T443 pAb generated against InsP $\mathrm{P}_{3} \mathrm{R} 1 \mathrm{C}$ termini (Kaznacheyeva et al., 1998) (Fig. 1C).

To determine the consequences of IC10 overexpression on $\mathrm{Ca}^{2+}$ signaling in YAC128 MSNs, we applied repetitive pulses of
$10 \mu \mathrm{M}$ glutamate to $\mathrm{WT}$ and YAC128 MSN primary cultures infected with Lenti-GFP or Lenti-GFP-IC10. The intracellular $\mathrm{Ca}^{2+}$ concentration in these experiments was continuously monitored by fura- 2 imaging, and the data are presented as 340 / 380 fura- 2 ratios plotted versus time in the experiment. We observed that basal $\mathrm{Ca}^{2+}$ levels before glutamate application were not significantly affected by genotype of MSN or GFP/GFP-IC10 expression (Fig. 2 E). Consistent with our previous results (Tang et al., 2005, 2007; Zhang et al., 2008), repetitive pulses of $10 \mu \mathrm{M}$ glutamate caused significant elevation of basal $\mathrm{Ca}^{2+}$ levels in YAC128 MSNs infected with Lenti-GFP (Fig. 2B), with much smaller $\mathrm{Ca}^{2+}$ increases in the WT MSNs infected with Lenti-GFP (Fig. $2 \mathrm{~A}$ ). On average, basal $\mathrm{Ca}^{2+}$ levels after 20 pulses of $10 \mu \mathrm{M}$ glutamate were equal to $0.40 \pm 0.03(n=46)$ for WT/GFP MSNs (Fig. $2 E)$ and $0.58 \pm 0.13(n=50)$ for YAC128/GFP MSNs (Fig. $2 E)$. Infection with Lenti-GFP-IC10 had no significant effect on glutamate-induced $\mathrm{Ca}^{2+}$ signals in WT MSNs (Fig. 2C), but stabilized $\mathrm{Ca}^{2+}$ responses in YAC128 MSNs (Fig. $2 \mathrm{D}$ ). On average, basal $\mathrm{Ca}^{2+}$ levels after 20 glutamate pulses were equal to $0.42 \pm$ 
$0.04(n=42)$ in YAC128 MSNs infected with Lenti-GFP-IC10 (Fig. 2E). On average, basal $\mathrm{Ca}^{2+}$ levels after 20 pulses of glutamate were significantly $(p<0.05)$ higher in YAC128/GFP MSNs than in either WT/GFP or YAC128/GFP-IC10 MSNs (Fig. 2E). These results indicated that expression of IC10 fragment specifically stabilized deranged glutamateinduced $\mathrm{Ca}^{2+}$ signaling in YAC128 MSNs.

\section{Expression of GFP-IC10 protects \\ YAC128 MSNs from \\ glutamate-induced apoptosis}

To test neuroprotective effects of Lenti-GFPIC10, we took advantage of an in vitro $\mathrm{HD}$ model that we developed previously (Tang et al., 2005). In these experiments, WT and YAC128 MSN cultures were infected with Lenti-GFP or Lenti-GFP-IC10 at 7DIV and 11DIV. At 14DIV, WT and YAC128 MSN cultures were treated by 0,100 , or $250 \mu \mathrm{M}$ glutamate for 7-8 h, and the cell death was analyzed by TUNEL-TMR staining (red) and DAPI nuclear counterstaining (blue). The control WT and YAC128 MSN cultures were treated by vehicle solution instead of lentiviruses. Consistent with the previous studies (Tang et al., 2005), a fraction of TUNEL-positive nuclei was significantly higher in YAC128 MSN cultures than in WT MSN cultures following exposure to glutamate (Fig. $3 A$, vehicle). Infection with LentiGFP had no significant effect on apoptosis of WT or YAC128 MSNs (Fig. 3A,B). Infection with Lenti-GFP-IC10 had no significant effect on cell death of WT MSNs, but drastically reduced glutamate-induced apoptosis of YAC128 MSNs (Fig. 3A,C). Thus, we concluded that expression of GFP-IC10 had specific neuroprotective effect in cellular model of HD.

Expression of GFP-IC10 in mouse striatum disrupts InsP $_{3} \mathrm{R} 1-\mathrm{Htt}^{\text {exp }}$ complex

To investigate the long-term effects of GFP-IC10 expression in the YAC128 mouse model of HD, we generated recombinant serotype 1 adeno-associated viruses (AAV1) viral vectors expressing GFP-IC10 fusion protein and control GFP protein (see Materials and Methods for details). Generated AAV1-GFP-IC10 and AAV1GFP viruses were stereotaxically injected to striatal region of wild-type mice at 2 months of age (see Materials and Methods for details). The injected mice were then transcardially perfused at 2, 4 , and 9 months after AAV1 injection. The extend of expression was evaluated by GFP imaging (Fig. 4A). In addition, the expression of GFP and GFP-IC10 were further analyzed by Western blotting of striatal lysates at 1, 2, 4, 6, and 9 months after AAV1 injection (Fig. $4 B$ ). Analysis of coronal brain sections from injected mice showed widespread transduction in striatum $(\sim 60 \%$

B

\section{2 months after rAAV injection}
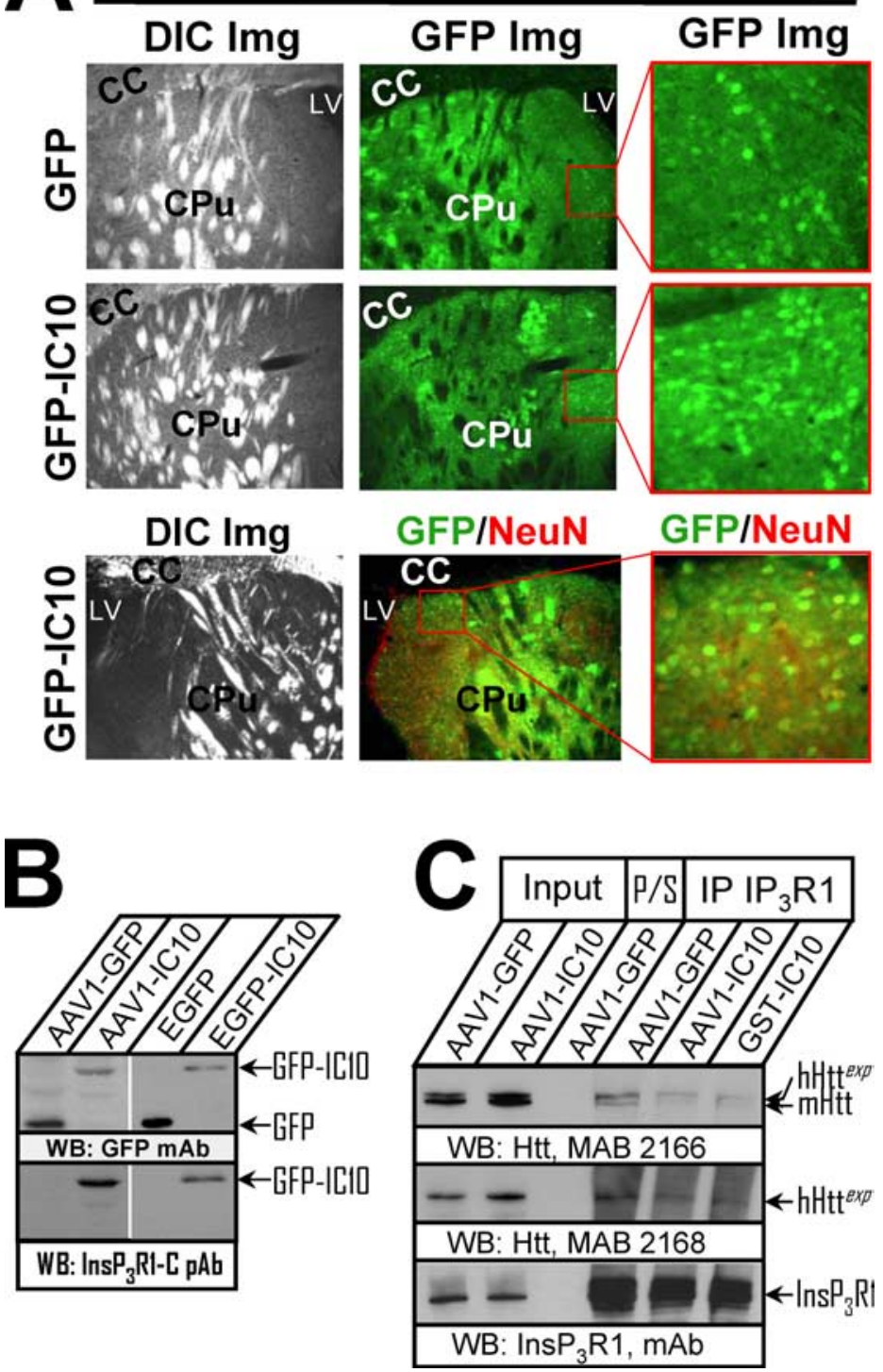

Figure 5. Striatal GFP-IC10 expression disrupts Ins $\mathrm{P}_{3} \mathrm{R} 1-\mathrm{Htt} \mathrm{exp}^{\mathrm{exs}}$ asciation in vivo. $\boldsymbol{A}, \mathrm{AAV} 1-\mathrm{GFP}$ or AAV1-IC10 brain expression pattern. GFP imaging (green) confirms widespread transduction of GFP and GFP-IC10 proteins in striatal region 2 months after infection. Staining with NeuN mAb is used to visualize the neuronal nuclei (red). CC, Corpus callosum; LV, lateral ventricle; $C P u$, striatum. B, GFP and GFP-IC10 protein expression. Striata of AAV1-GFP-and AAV1-GFP-IC10-injected mice were dissected out. The striatal lysates were analyzed by Western blotting with anti-GFP mAb (top) and T443 anti-InsP ${ }_{3} \mathrm{R} 1 \mathrm{pAb}$ (bottom). Thirty-five micrograms of total protein was loaded for each sample. The lysates from HEK293 cells transfected with pEGFP and pEGFP-IC10 plasmids were used as reference controls. C, GFP-IC10 reduces $\operatorname{InsP}_{3} \mathrm{R} 1-\mathrm{Htt}{ }^{\mathrm{exp}}$ association in YAC128 striatum. Two months after injection with AAV1-GFP and AAV1-GFP-IC10 viruses, the striatal lysates were prepared and used in immunoprecipitation experiments with $\mathrm{T} 443$ anti-InsP $\mathrm{P}_{3} \mathrm{R} 1 \mathrm{pAb}$ or corresponding preimmune sera (IP/S). The precipitated fractions were resolved by $4-12 \%$ continuous gradient SDS-PAGE and analyzed by Western blotting with MAB2166 (Millipore Bioscience Research Reagents, against human/mouse Htt protein, top). The same membrane was stripped and reprobed with MAB2168 (Millipore Bioscience Research Reagents, against human/monkey $\mathrm{Htt}$ protein, middle) and anti-InsP ${ }_{3} \mathrm{R} 1 \mathrm{mAb}$ (NeuroMab 75-035, bottom). The input lanes contained $1 / 10$ of lysates used in immunoprecipitation reactions.

of striatum) (Fig. 4A; Fig. 5A, first and second rows). Counterstaining with $\mathrm{NeuN} \mathrm{mAb}$ (red) revealed that $\sim 80 \%$ of striatal neurons in injected region were infected (Fig. $5 A$, third row). Western-blotting analysis of striatal lysates prepared from injected mice confirmed the sustained expression of GFP and GFPIC10 proteins in AAV-injected mice (Figs. $4 B, 5 B$ ).

As an additional control, we evaluated effects of sustained expression of GFP-IC10 on Htt-128Q expression levels in YAC128 mice. In these experiments, we prepared striatal lysates 


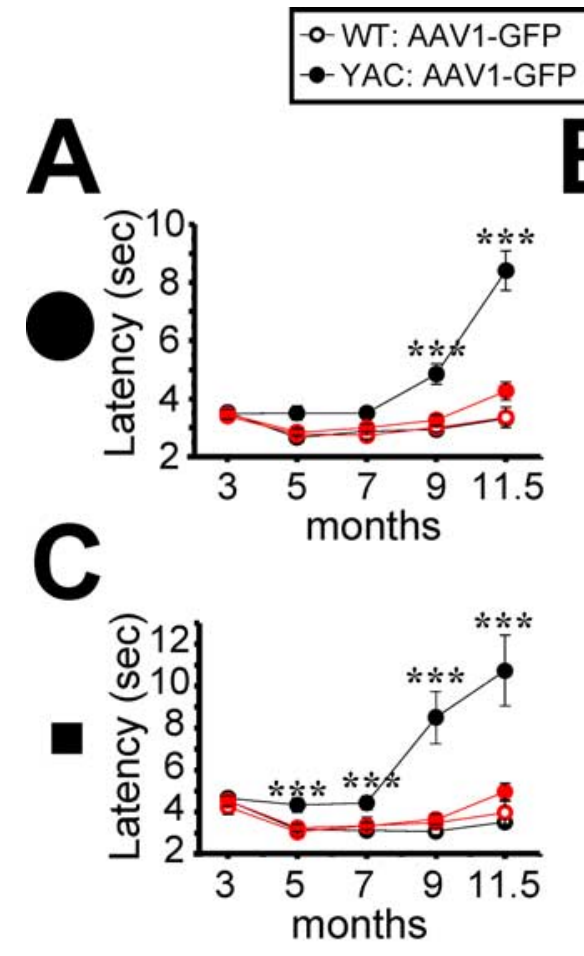

- WT: AAV1-IC10

$\rightarrow$ YAC: AAV1-IC10

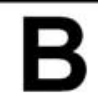

A
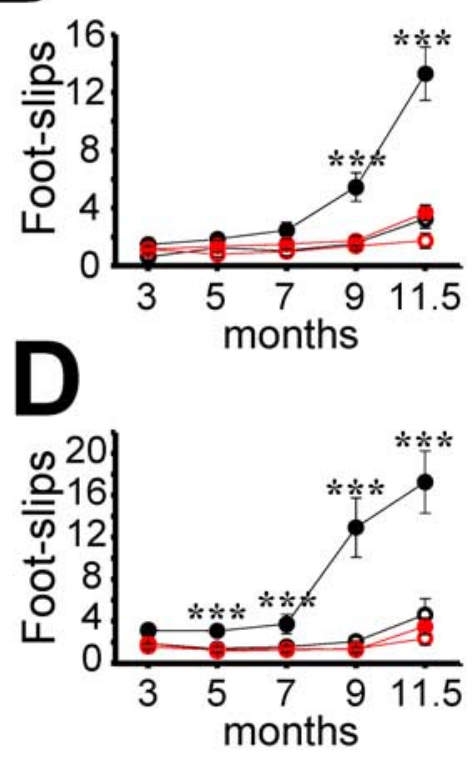
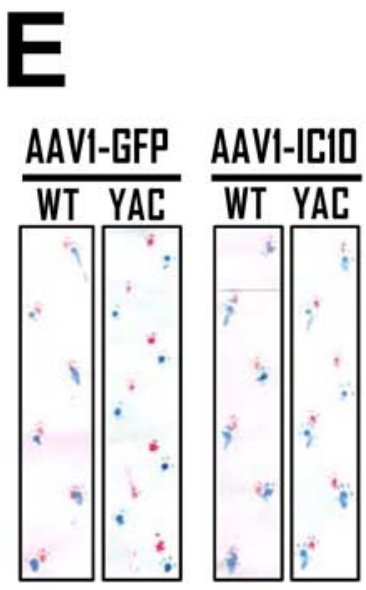
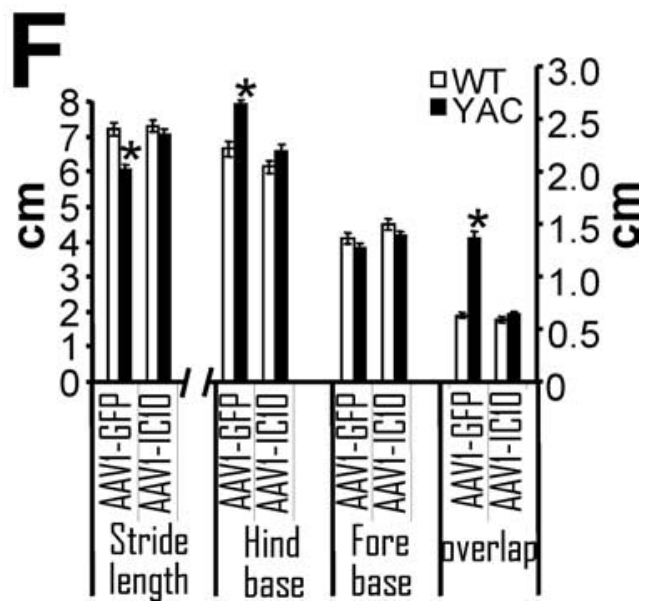

Figure 6. Motor coordination assays of WT and YAC128 mice. $A-D$, Balance beam assay. The average time to cross the beam $(\boldsymbol{A}$, $C$ and the average number of foot slips on the beam $(\boldsymbol{B}, \boldsymbol{D})$ are shown for beam-walking experiments performed with the $11 \mathrm{~mm}$ round plastic beam $(\boldsymbol{A}, \boldsymbol{B})$ and $5 \mathrm{~mm}$ square wood beam $(\boldsymbol{C}, \boldsymbol{D})$. The data for WT/GFP mice (open black circles), YAC/GFP mice (filled black circles), WT/IC10 mice (open red circles), and YAC/IC10 mice (filled red circles) are shown as mean \pm SEM ( $n=$ number of mice; see Table 1) at 3, 5, 7, 9, and 11.5 month time points. ${ }^{* *} p<0.05$, significant differences between YAC/GFP group and YAC/IC10 group. $E, F$, Gait analysis. $E$, The footprints for AAV1-GFP and AAV1-IC10 groups are shown for both WT and YAC128 mice at the 11.5 month time point. $\boldsymbol{F}$, The footprint patterns were assessed quantitatively by four measurements: stride length, hind base width, front base width, and front/hind footprint overlap. The front base width measurements are similar for all four groups of mice. YAC/GFP mice show significantly $(p<0.01)$ shorter stride lengths, increased hind base, and greater forepaw/hindpaw overlap compared with WT/GFP mice. YAC128 mice injected with AAV1-GFP-IC10 exhibited stride lengths, hind base, and forepaw/hindpaw overlap similar to those from WT/GFP mice. Data for each measure are presented as mean \pm SEM $(n=$ number of mice; see Table 1). ${ }^{*} p<0.01$, significantly different from WT/GFP and YAC/IC10 groups.

from 8-month-old YAC128 mice injected with AAV1-GFP and AAV1-IC10 viruses at 2 months of age. Western blotting with $\mathrm{mAb}$ against human Htt confirmed similar levels of Htt-128 expression in YAC128 striatum injected with AAV1-GFP and AAV1-IC10 viruses (data not shown). These results indicated that long-term expression of GFP-IC10 peptide does not significantly reduce $\mathrm{Htt}-128$ expression levels in vivo.

As mutant $\mathrm{Htt}^{\exp }$ specifically binds to C-terminal region of
InsP $P_{3}$ R1 (Tang et al., 2003), introduction of IC10 peptide into HD MSNs is expected to disrupt InsP ${ }_{3} \mathrm{R} 1-\mathrm{Htt}^{\exp }$ association. To test this hypothesis, we performed a series of immunoprecipitation experiments with InsP $_{3} \mathrm{R} 1 \mathrm{pAb}$ using striatal lysates prepared from YAC128 mouse injected with AAV1-GFP or AAV1-GFP-IC10 viruses. The precipitated fractions were analyzed by Western blotting with huntingtinspecific $\mathrm{mAb}$. In additional control experiments, $50 \mu \mathrm{g} / \mathrm{ml}$ GST-IC10 recombinant protein was included in immunoprecipitation reaction as indicated. We found that both $\mathrm{Htt}$ and $\mathrm{Htt}^{\exp }$ proteins are $\mathrm{co}^{-}$ immunoprecipitated with $\mathrm{Ins}_{3} \mathrm{R} 1$ from YAC128/GFP striatal lysate, with a significantly higher amount of precipitated $\mathrm{Htt}^{\exp }$ protein (Fig. 5C). This is consistent with our previous findings that mutant $\mathrm{Htt}^{\text {exp }}$ has significantly higher affinity for $\mathrm{InsP}_{3} \mathrm{R} 1$ than wild-type $\mathrm{Htt}$ (Tang et al., 2003). GFP-IC10 expression in YAC128 striatum significantly reduced the amounts of precipitated $\mathrm{Htt}^{\exp }$ (Fig. 5C), indicating that GFP-IC10 expression in YAC128 striatum disrupts InsP $\mathrm{P}_{3} \mathrm{R} 1-\mathrm{Htt}{ }^{\exp }$ complex in vivo. The effects of GFP-IC10 expression were similar to effects of GSTIC10 addition to immunoprecipitation reaction (Fig. 5C). Following Western blotting with anti-Htt antibodies, the membranes were stripped and reblotted with anti-InsP $\mathrm{P}_{3} \mathrm{R} 1 \mathrm{mAb}$. These experiments confirmed that equal amounts of Ins $\mathrm{P}_{3} \mathrm{R} 1$ were immunoprecipitated in experiments with striatal lysates from YAC128 mice injected with AAV1-GFP and AAV1-IC10 viruses (Fig. 5C).

Striatal expression of GFP-IC10 rescues motor coordination phenotype of YAC128 mice

To determine the effects of AAV1-GFP and AAV1-GFP-IC10 on the motor coordination phenotype of YAC128 mice (Slow et al., 2003; Tang et al., 2007), female WT and YAC128 mice were bilaterally and stereotaxically injected into striatal region with either AAV1-GFP or AAV1-GFPIC10 viruses. The injections were performed at 7-8 weeks of age for all mice, with 15 mice in each of the four injected groups. In control experiments, we confirmed that a single injection of AAV1GFP or AAV1-GFP-IC10 viruses results in persistent expression of GFP or GFP-IC10 proteins for at least 9 months following initial injection (Fig. $4 A, B$ ). The injected mice were then given 2 weeks for recovery from surgery followed by motor coordination assays starting at 11-12 weeks of age. Balance beam assay was used to compare the fine motor coordination and balance capabilities among different groups of mice as we previously described for an L-dopa/TBZ trial of YAC128 mice (Tang et al., 
2007). The latency to traverse the beam and the number of foot slips while walking on beam were recorded for the $11 \mathrm{~mm}$ round beam and $5 \mathrm{~mm}$ square beam. Beam-walking assays were repeated every 2 months until mice were 11.5 months old. We found that YAC128 mice injected with AAV1-GFP virus exhibited progressive impairments in beam-walking ability (longer beam traverse latencies and increased number of foot slips) with age and beam difficulty compared with WT mice injected with the same AAV1-GFP virus. The significant differences $(p<0.05)$ between beam performance of YAC128/GFP and WT/GFP groups were observed at 7,9 , and 11.5 months of age on the 11 $\mathrm{mm}$ round beam (Fig. $6 A, B$ ), and at 5, 7, 9, and 11.5 months of age on the $5 \mathrm{~mm}$ square beam (Fig. $6 C, D$ ). In contrast, YAC128/ IC10 mice performed as well as WT/GFP or WT/IC10 mice at all levels of task difficulty until 9 months of age and significantly better $(p<0.01)$ than YAC128/GFP group at 9 and 11.5 months of age on the $11 \mathrm{~mm}$ round beam (Fig. $6 A, B$ ) and at 5, 7, 9, and 11.5 months of age on the $5 \mathrm{~mm}$ square beam (Fig. $6 C, D$ ). These results indicated that striatal expression of GFP-IC10 protein significantly improved the balance beam performance of aging YAC128 mice. Striatal injection of AAV1-GFP and AAV1-GFPIC10 injection into WT mice had no significant effects on balance beam performance of these mice, suggesting that GFP or GFPIC10 expression is not toxic to striatal neurons.

In addition to the balance beam coordination assay, we also assessed gait abnormalities in all four groups of mice by using analysis of footprint pattern at 11.5 months of age. The footprint patterns (Fig. $6 \mathrm{E}$ ) were analyzed quantitatively by four measurements: stride length, hind base width, front base width, and front/ hind footprint overlap (Fig. 6F). Consistent with our previous findings (Tang et al., 2007), our analysis revealed that 11.5month-old YAC128/GFP mice show significantly $(p<0.01)$ shorter stride lengths, increased hind base, and increased forepaw/hindpaw overlap compared with WT/GFP mice (Fig. 6 F). In contrast, YAC128 mice injected with AAV1-GFP-IC10 walked in stride lengths, hind base, and forepaw/hindpaw overlap similar to WT/GFP or WT/IC10 mice (Fig. $6 F$ ), indicating that striatal expression of GFP-IC10 rescued gait abnormalities in aging YAC128 mice.

\section{Striatal expression of GFP-IC10 reduces neuronal loss in aging YAC128 mice}

Selective loss of striatal MSNs is a major neuropathological hallmark of HD and characteristic feature of aging YAC128 mice (Slow et al., 2003). To evaluate effects of GFP-IC10 expression on neuropathology, at conclusion of behavioral analysis the mouse brains from all four groups of mice were removed from the skull and weighed after transcardial perfusion (Fig. 7A, Table 1). Consistent with the previous reports (Slow et al., 2003; Tang et al., 2007), YAC128/GFP mice showed significant reduction in brain weight compared with WT/GFP mice (Fig. 7A, Table 1). AAV1-GFP-IC10 injection into WT mice had no significant effect on brain weight of these mice (Fig. 7A, Table 1). There was some increase in brain weight of YAC128 mice injected with AAV1-GFP-IC10, but the difference did not reach a level of statistical significance compared with YAC128/GFP group (Fig. 7A, Table 1).

In the next series of experiments, we estimated a total MSN cell number in each of these groups by unbiased stereology approach. In these experiments, NeuN-positive neurons in striatum were counted blindly with respect to the nature of slices (genotype and viral vectors treatment). In agreement with the previous reports (Slow et al., 2003; Tang et al., 2007), YAC128
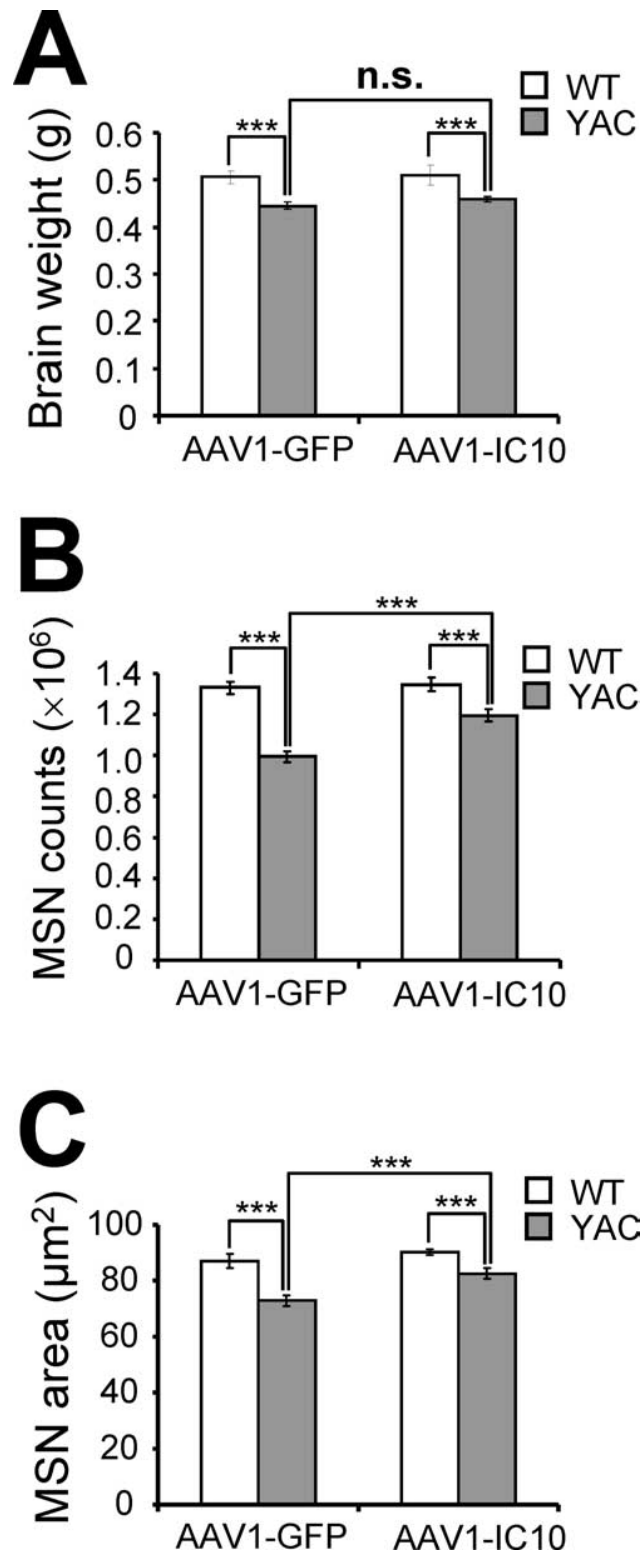

Figure 7. Neuropathological assessments in WT and YAC128 mice. $A$, Average brain weight of 11.5-month-old AAV1 trial mice. The brain weight of YAC/GFP mice is significantly reduced compared with WT/GFP group $(p<0.01)$. There was some increase in brain weight of YAC128 mice injected with AAV1-GFP-IC10, but the difference did not reach a level of statistical significance compared with YAC/GFP group. B, Average striatal neuronal counts of 11.5 -month-old AAV1 trial mice. YAC/GFP mice display significant striatal neuronal loss $(p<0.01)$ compared with WT/GFP mice. YAC128 mice injected with AAV1-GFP-IC10 exhibited significantly increased neuronal counts $(p<0.01)$ compared with control YAC/GFP mice but significantly reduced neuronal counts $(p<0.01)$ compared with WT/GFP mice. $C$, Average cross-sectional area of striatal neurons of 11.5-month-old AAV trial mice. YAC/GFP mice showed significant reduction in average neuronal cross-sectional areas ( $p<0.01)$ compared with WT/GFP mice. YAC/IC10 mice exhibited significantly larger MSN cross-sectional area $(p<0.01)$ than YAC/GFP group but significantly smaller MSN cross-sectional area $(p<0.01)$ than WT/GFP group. ${ }^{* *} p<$ 0.01. n.s., Not significant.

mice injected with AAV1-GFP showed significant striatal neuronal loss compared with WT/GFP or WT/IC10 mice (Fig. 7B, Table 1). The YAC128 mice injected with AAV1-GFP-IC10 virus exhibited significantly increased striatal neuronal counts compared with YAC128/GFP mice (Fig. 7B, Table 1), indicating that GFP-IC10 expression protected MSNs from cell death in YAC128 mice. 
Table 1. Neuropathological analysis of brains from AAV1-injected mice

\begin{tabular}{llllc}
\hline Group \# & Group name & Number of mice & Brain weight $(\mathrm{g})$ & Neuron count $\left(\times 10^{6}\right.$ cells) \\
\hline 1 & WT-GFP & 13 & $0.506 \pm 0.014$ & $1.331 \pm 0.030$ \\
2 & YAC-GFP & 15 & $0.445 \pm 0.006^{a}$ & $0.992 \pm 0.032^{a}$ \\
3 & WT-GFP-IC10 & 11 & $0.511 \pm 0.021$ & $1.347 \pm 0.027$ \\
4 & YAC-GFP-IC10 & 14 & $0.460 \pm 0.007^{a}$ & $12.88 \pm 1.87^{a}$ \\
\hline
\end{tabular}

Four groups of mice were tested in our experiments. At 7-8 weeks of age, WT and YAC128 mice were divided into two groups each and AAV1-GFP or AAV1-GFP-IC10 injection into striatum was performed. The average brain weights, striata neuronal counts, and striatal neuron cross-sectional areas were measured in 11.5-month-old WT and YAC128 mice at the conclusion of the behavioral trial. Several mice died following injection or during the behavioral stage of the trial and were not used in neuropathological analysis. The data are shown as mean $\pm \operatorname{SEM}(n=$ number of mice).

${ }^{a}$ Significantly different $(p<0.01)$ compared with WT groups.

${ }^{b}$ Significantly different $(p<0.01)$ compared with YAC-GFP groups.

Additional stereological analysis revealed significant reduction in average neuronal cross-sectional areas in YAC128/GFP mice compared with WT/GFP mice (Fig. 7C, Table 1). These results are consistent with our previous findings (Tang et al., 2007) and with the recent report analysis performed with 129 strain YAC128 mice (Van Raamsdonk et al., 2007). Interestingly, the MSN cross-sectional area was significantly increased in YAC128/IC10 mice compared with YAC128/GFP mice (Fig. 7C, Table 1). These results indicate that expression of GFP-IC10 not only protects YAC128 MSNs from cell death but also prevents MSN shrinkage in aging YAC128 mice. This is in contrast to our previous study of dopamine antagonist tetrabenazine, which reduced cell loss of aging YAC128 MSNs but did not prevent cell shrinkage (Tang et al., 2007).

Mutant huntingtin aggregation and inclusion formation are hallmarks of Huntington's disease. YAC128 mice exhibited significantly increased nuclear mutant huntingtin staining at 12 months of age and significantly increased nuclear huntingtin inclusions at 18 months of age (Slow et al., 2003). To test whether the expression of GFP-IC10 peptide could modulate the mutant huntingtin aggregation, the brain sections from 12-month-old WT and YAC128 mice injected with AAV1-GFP or AAV1-IC10 viruses were stained with MAB5374, an antibody that recognizes $\mathrm{N}$-terminal huntingtin and is highly specific for aggregates. Consistent with the previous results (Slow et al., 2003), nuclear huntingtin staining was observed in 12-month-old YAC128 mice but not in WT mice injected with AAV1-GFP (supplemental Fig. $1 A, B$, available at www.jneurosci.org as supplemental material). The striatal region of YAC128 mice expressing GFP-IC10 had significantly decreased nuclear huntingtin staining (supplemental Fig. 1D, available at www.jneurosci.org as supplemental material).

\section{Discussion}

$\mathrm{Ca}^{2+}$ plays an important role in neuronal signaling (Berridge, 1998), and perturbed $\mathrm{Ca}^{2+}$ homeostasis have been linked to many neurodegenerative disorders, including Alzheimer's (Bezprozvanny and Mattson, 2008), Parkinson's (Surmeier, 2007), and Huntington's (Bezprozvanny and Hayden, 2004) diseases. While various pathways have been implicated in HD (Tobin and Signer, 2000; Ross, 2002; Harjes and Wanker, 2003; Sugars and Rubinsztein, 2003), deranged neuronal $\mathrm{Ca}^{2+}$ signaling seems to be one of the early dysfunctions in HD (Bezprozvanny and Hayden, 2004). Thus $\mathrm{Ca}^{2+}$ signaling pathway constitutes new therapeutic targets for treatment of HD (Tang et al., 2005; Wu et al., 2006). Expression of $\mathrm{Htt}^{\text {exp }}$ leads to an increase in activity of NR1A/NR2B subtype of NMDAR (Zeron et al., 2002; Milnerwood and Raymond, 2007; Zhang et al., 2008) and sensitization of InsP $\mathrm{P}_{3} \mathrm{R} 1$ (Tang et al., 2003). The influence of $\mathrm{Htt}^{\exp }$ on NMDAR is most likely caused by altered NMDA receptor trafficking (Fan et al., 2007). The sensitization of $\operatorname{InsP}_{3} \mathrm{R} 1$ is due to specific interaction between the C-terminal cytosolic tail of $\mathrm{InsP}_{3} \mathrm{R} 1$ (IC10 fragment) and mutant $\mathrm{Htt}^{\exp }$ (Tang et al., 2003). The association of $\mathrm{Htt}^{\exp }$ with $\mathrm{InsP}_{3} \mathrm{R} 1$ dramatically increases the sensitivity of $\operatorname{Ins}_{3} \mathrm{R} 1$ to activation by $\mathrm{InsP}_{3}$ (Tang et al., 2003). As a result, MSN cultures from the YAC128 transgenic HD mouse model display enhanced $\mathrm{Ca}^{2+}$ responses to glutamate and increased sensitivity to glutamate-induced apoptosis (Tang et al., 2005, 2007; Wu et al., 2006; Zhang et al., 2008). Considering the important role of dysregulation of $\mathrm{InsP}_{3} \mathrm{R} 1$-mediated $\mathrm{Ca}^{2+}$ signaling in HD pathogenesis, normalization of intracellular neuronal $\mathrm{Ca}^{2+}$ signaling is a promising potential strategy for HD treatment (Bezprozvanny and Hayden, 2004). Indeed, pharmacological inhibition of $\mathrm{InsP}_{3} \mathrm{R}$ protected YAC128 MSNs from glutamate-induced apoptosis in vitro and indicated that $\operatorname{Ins}_{3} \mathrm{R}$ could be considered as a potential target for treatment of HD (Tang et al., 2005).

Since dysregulation of $\operatorname{Ins}_{3} \mathrm{R} 1$-mediated $\mathrm{Ca}^{2+}$ signaling in HD MSNs is due to the pathological association between $\mathrm{Htt}^{\exp }$ and $\mathrm{InsP}_{3} \mathrm{R} 1 \mathrm{C}$ terminus, introduction of IC10 fragment into HD MSNs is expected to disrupt InsP $\mathrm{P}_{3} \mathrm{R} 1-\mathrm{Htt}^{\exp }$ association and prevent $\mathrm{Ca}^{2+}$ overload and apoptosis of HD MSNs. Consistent with these predictions, in our experiments expression of GFP-IC10 fusion protein reduced the amount of $\mathrm{Htt}^{\exp }$ coprecipitated with Ins $\mathrm{P}_{3} \mathrm{R} 1$ from striatal lysates of YAC128 mouse (Fig. 5C). We further found that overexpression of GFP-IC10 stabilized glutamate-induced $\mathrm{Ca}^{2+}$ signals in YAC128 MSNs (Fig. 2), protected YAC128 MSNs from glutamate-induced apoptosis (Fig. 3 ), alleviated motor coordination deficits in aging YAC128 mice (Fig. 6) and protected YAC128 MSNs from cell loss and shrinkage in vivo (Fig. 7). All these results confirmed the importance of $\mathrm{InsP}_{3} \mathrm{R} 1$ association with $\mathrm{Htt}^{\text {exp }}$ for pathogenesis of the disease.

To determine whether disruption of Ins $_{3} \mathrm{R} 1-\mathrm{Htt}^{\exp }$ interaction is the only factor attributing to the neuroprotective effects of IC10 peptide, we also examined the effects of GFP-IC10 overexpression on nuclear accumulation of $\mathrm{Htt}^{\exp }$ fragments in YAC128 mice striatal neurons. We found that striatal expression of GFP-IC10 in YAC128 mice significantly reduced the nuclear mutant huntingtin staining (supplemental Fig. $1 D, E$, available at www.jneurosci.org as supplemental material). The mechanisms responsible for blocking effects of IC10 peptide on nuclear huntingtin aggregation are not clear. It is possible that nuclear accumulation of $\mathrm{Htt}^{\exp }$ fragments is downstream from $\mathrm{Ca}^{2+}$-induced cell stress, and reduction in nuclear $\mathrm{Htt}^{\exp }$ fragment amounts may reflect stabilization of neuronal $\mathrm{Ca}^{2+}$ signaling following GFP-IC10 overexpression. Our previous biochemical data indicated that IC10 peptide binds Htt ${ }^{\exp }$ (Tang et al., 2003), and it is feasible that overexpression of GFP-IC10 reduces $\mathrm{Htt}^{\text {exp }}$ aggregation and nuclear accumulation by direct $\mathrm{Htt}^{\text {exp}}$-binding mechanism. The reduction of $\mathrm{Htt}^{\text {exp }}$ fragment nuclear accumulation (supplemental Fig. 1, available at www.jneurosci.org as supple- 
mental material) may provide an additional protective mechanism of GFP-IC10 that works in concert with $\mathrm{Ca}^{2+}$ signaling stabilizing effects (Fig. 2).

AAV1 vectors were delivered into striatum of YAC128 mice at 2 months of age, when these mice are presymptomatic (Slow et al., 2003; Tang et al., 2007). Our in vivo results demonstrate that viral delivery of GFP-IC10 to the striatum of presymptomatic mice can prevent the pathological and functional degeneration seen in YAC128 transgenic model of HD. Clinical studies suggest that HD symptoms can occur before the loss of striatal neurons due to neuronal dysfunction (Albin et al., 1990, 1992). The alleviation of motor coordination deficits and protection from neuronal loss in YAC128 mice resulting from AAV1-GFP-IC10 injections suggest that early aspects of neuronal malfunction and/or the degenerative process that mediate symptom onset could be prevented by presymptomatic treatment with IC10 peptide. Our results also suggest that the phenotype of YAC128 mice is primarily determined by striatal pathology. In our experiments striatal-specific expression of GFP-IC10 protein was able to rescue most of the motor coordination phenotype in these mice and to significantly reduce striatal neuronal loss. These results argue in favor of striatal model of $\mathrm{Htt}^{\exp }$ toxicity, consistent with the phenotype of striatal-specific transgenic model of HD (Brown et al., 2008) and with benefits observed as a result of striatal-specific $\mathrm{Htt}^{\text {exp }}$ knockdown by RNAi (Harper et al., 2005). However, some non-cell autonomous pathological effects of mutant $\mathrm{Htt}^{\exp }(\mathrm{Gu}$ et al., 2005, 2007) cannot be excluded by our results.

In summary, we demonstrated that overexpression of GFPIC10 fusion protein can stabilize $\mathrm{Ca}^{2+}$ signaling and protect YAC128 MSNs from cell death in vitro and in vivo. Our results further validate $\mathrm{Ins}_{3} \mathrm{R} 1$ as potential $\mathrm{HD}$ therapeutic target and also support IC10 peptide as a novel HD therapeutic agent.

\section{References}

Albin RL, Young AB, Penney JB, Handelin B, Balfour R, Anderson KD, Markel DS, Tourtellotte WW, Reiner A (1990) Abnormalities of striatal projection neurons and $\mathrm{N}$-methyl-D-aspartate receptors in presymptomatic Huntington's disease. N Engl J Med 322:1293-1298.

Albin RL, Reiner A, Anderson KD, Dure LS 4th, Handelin B, Balfour R, Whetsell WO Jr, Penney JB, Young AB (1992) Preferential loss of striato-external pallidal projection neurons in presymptomatic Huntington's disease. Ann Neurol 31:425-430.

Berridge MJ (1998) Neuronal calcium signaling. Neuron 21:13-26.

Bezprozvanny I, Hayden MR (2004) Deranged neuronal calcium signaling and Huntington disease. Biochem Biophys Res Commun 322:1310-1317.

Bezprozvanny I, Mattson MP (2008) Neuronal calcium mishandling and the pathogenesis of Alzheimer's disease. Trends Neurosci 31:454-463.

Brown TB, Bogush AI, Ehrlich ME (2008) Neocortical expression of mutant huntingtin is not required for alterations in striatal gene expression or motor dysfunction in a transgenic mouse. Hum Mol Genet 17:3095-3104.

Fan MM, Fernandes HB, Zhang LY, Hayden MR, Raymond LA (2007) Altered NMDA receptor trafficking in a yeast artificial chromosome transgenic mouse model of Huntington's disease. J Neurosci 27:3768-3779.

Gu X, Li C, Wei W, Lo V, Gong S, Li SH, Iwasato T, Itohara S, Li XJ, Mody I, Heintz N, Yang XW (2005) Pathological cell-cell interactions elicited by a neuropathogenic form of mutant Huntingtin contribute to cortical pathogenesis in HD mice. Neuron 46:433-444.

Gu X, André VM, Cepeda C, Li SH, Li XJ, Levine MS, Yang XW (2007) Pathological cell-cell interactions are necessary for striatal pathogenesis in a conditional mouse model of Huntington's disease. Mol Neurodegener 2:8.

Harjes P, Wanker EE (2003) The hunt for huntingtin function: interaction partners tell many different stories. Trends Biochem Sci 28:425-433.
Harper SQ, Staber PD, He X, Eliason SL, Martins IH, Mao Q, Yang L, Kotin RM, Paulson HL, Davidson BL (2005) RNA interference improves motor and neuropathological abnormalities in a Huntington's disease mouse model. Proc Natl Acad Sci U S A 102:5820-5825.

Kaznacheyeva E, Lupu VD, Bezprozvanny I (1998) Single-channel properties of inositol $(1,4,5)$-trisphosphate receptor heterologously expressed in HEK-293 cells. J Gen Physiol 111:847-856.

Milnerwood AJ, Raymond LA (2007) Corticostriatal synaptic function in mouse models of Huntington's disease: early effects of huntingtin repeat length and protein load. J Physiol 585:817-831.

Ross CA (2002) Polyglutamine pathogenesis: emergence of unifying mechanisms for Huntington's disease and related disorders. Neuron $35: 819-822$.

Slow EJ, van Raamsdonk J, Rogers D, Coleman SH, Graham RK, Deng Y, Oh R, Bissada N, Hossain SM, Yang YZ, Li XJ, Simpson EM, Gutekunst CA, Leavitt BR, Hayden MR (2003) Selective striatal neuronal loss in a YAC128 mouse model of Huntington disease. Hum Mol Genet 12:1555-1567.

Sugars KL, Rubinsztein DC (2003) Transcriptional abnormalities in Huntington disease. Trends Genet 19:233-238.

Surmeier DJ (2007) Calcium, ageing, and neuronal vulnerability in Parkinson's disease. Lancet Neurology 6:933-938.

Tang TS, Tu H, Chan EY, Maximov A, Wang Z, Wellington CL, Hayden MR, Bezprozvanny I (2003) Huntingtin and huntingtin-associated protein 1 influence neuronal calcium signaling mediated by inositol- $(1,4,5)$ triphosphate receptor type 1. Neuron 39:227-239.

Tang TS, Slow E, Lupu V, Stavrovskaya IG, Sugimori M, Llinás R, Kristal BS, Hayden MR, Bezprozvanny I (2005) Disturbed Ca2 + signaling and apoptosis of medium spiny neurons in Huntington's disease. Proc Natl Acad Sci U S A 102:2602-2607.

Tang TS, Chen X, Liu J, Bezprozvanny I (2007) Dopaminergic signaling and striatal neurodegeneration in Huntington's disease. J Neurosci 27:7899-7910.

The Huntington's Disease Collaborative Research Group (1993) A novel gene containing a trinucleotide repeat that is expanded and unstable on Huntington's disease chromosomes. Cell 72:971-983.

Tobin AJ, Signer ER (2000) Huntington's disease: the challenge for cell biologists. Trends Cell Biol 10:531-536.

Urabe M, Ding C, Kotin RM (2002) Insect cells as a factory to produce adeno-associated virus type 2 vectors. Hum Gene Ther 13:1935-1943.

Van Raamsdonk JM, Metzler M, Slow E, Pearson J, Schwab C, Carroll J, Graham RK, Leavitt BR, Hayden MR (2007) Phenotypic abnormalities in the YAC128 mouse model of Huntington disease are penetrant on multiple genetic backgrounds and modulated by strain. Neurobiol Dis 26:189-200.

Vonsattel JP, DiFiglia M (1998) Huntington disease. J Neuropathol Exp Neurol 57:369-384.

Wu J, Tang T, Bezprozvanny I (2006) Evaluation of clinically-relevant glutamate pathway inhibitors in in vitro model of Huntington's disease. Neurosci Lett 407:219-223.

Xia H, Mao Q, Eliason SL, Harper SQ, Martins IH, Orr HT, Paulson HL, Yang L, Kotin RM, Davidson BL (2004) RNAi suppresses polyglutamineinduced neurodegeneration in a model of spinocerebellar ataxia. Nat Med $10: 816-820$.

Young $\mathrm{AB}$ (2003) Huntingtin in health and disease. J Clin Invest 111:299-302.

Zeron MM, Hansson O, Chen N, Wellington CL, Leavitt BR, Brundin P, Hayden MR, Raymond LA (2002) Increased sensitivity to $N$-methyl-Daspartate receptor-mediated excitotoxicity in a mouse model of Huntington's disease. Neuron 33:849-860.

Zhang H, Li Q, Graham RK, Slow E, Hayden MR, Bezprozvanny I (2008) Full length mutant huntingtin is required for altered $\mathrm{Ca} 2+$ signaling and apoptosis of striatal neurons in the YAC mouse model of Huntington's disease. Neurobiol Dis 31:80-88.

Zolotukhin S, Byrne BJ, Mason E, Zolotukhin I, Potter M, Chesnut K, Summerford C, Samulski RJ, Muzyczka N (1999) Recombinant adenoassociated virus purification using novel methods improves infectious titer and yield. Gene Ther 6:973-985. 